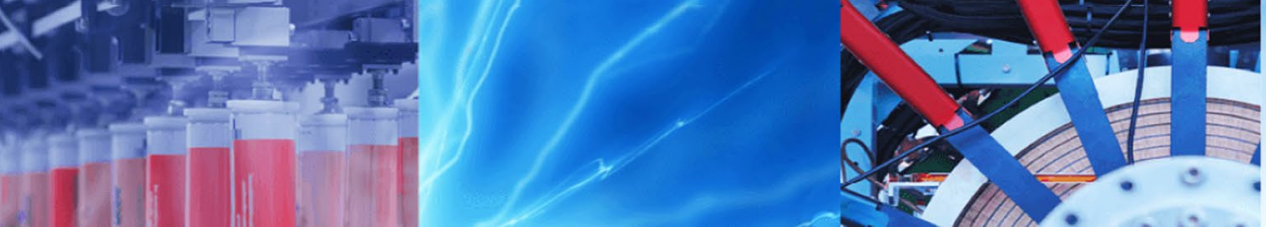

Research Article

\title{
Investigation on effective operating variables in gamma-type Stirling engine performance: a simulation approach
}

\author{
Mohammad Hadi Katooli $^{1} \cdot$ Reza Askari Moghadam ${ }^{1}\left[\right.$ Mazdak Hooshang $^{1}$
}

Received: 4 November 2019 / Accepted: 13 March 2020 / Published online: 20 March 2020

(c) Springer Nature Switzerland AG 2020

\begin{abstract}
The Stirling engine is one of the engines that has become popular due to its many advantages. Nowadays, lack of fossil fuels has led to a lot of attention to the use of renewable energies. For this reason, solar energy has drawn a lot of attention to be used as the Stirling engine heat source. The purpose of this paper is to investigate the performance of a proposed Stirling engine in different engine speeds, pressures, and working fluids. The proposed Stirling engine is of gamma-type. This engine is simulated using the Nlog code which is written for this engine in MATLAB work space. This code was validated by experimental data in our previous works. The investigated fluids in this study are helium, nitrogen, and hydrogen. It was found that the best fluid for the proposed Stirling engine is hydrogen, and the best engine speed is $1300 \mathrm{rpm}$. Also, the higher the engine pressure, the more the output work will be.
\end{abstract}

Keywords Mechatronics $\cdot$ Stirling engine $\cdot$ Working fluid $\cdot$ Renewable energy

\section{Introduction}

The Stirling engine is a thermal engine that, despite its simplicity, has passed a long way to evolve. The cycle was first invented by Robert Sterling in 1816 [1, 2]. Compression and expansion processes are carried out and include an ideal thermal recovery, this cycle is the closest cycle to the Carnot cycle [3-6]. This type of engine has not been in a good position over the past century compared to other types of engines, but with engineering advancements and the introduction of new techniques and mechanisms for the implementation of this thermodynamic cycle, in addition to solving the problems encountered by the engine, its widespread benefits became evident. Because of the many problems involved in making the device that could work with this cycle, the Stirling engine could not compete with the internal engines [2]. The Stirling engine is compatible with any type of heat source in comparison with other internal combustion engines and works with less noise. If this engine is used as a propulsion engine in vehicles, the level of emissions will be greatly reduced. The main advantages of the Stirling engine are the ability to use a variety of fossil and non-fossil fuels, low emissions, and quiet performance with low vibrations. These advantages have led to the use of the Stirling engine in specific industries, such as the aerospace industry, submarine construction, and military industry.

The first attempt to model and analyze the Stirling engine cycle was presented fifty years after its invention by Schmidt in 1871 [7]. Continuing in 1963, Finkelstein simulated the Stirling engine analogically and in 1972 managed to provide a computer simulation of his model [8]. After that, major efforts were focused on the simulation of Stirling engine on the use of different analysis methods such as Computational Fluid Dynamics (CFD) and numerical methods [9, 10], Finite Element Method (FDM) [11], and the use of experimental results in simulations. Due to the considerable influence of thermodynamic, thermal,

Reza Askari Moghadam, r.askari@ut.ac.ir; Mohammad Hadi Katooli, hadi.katoly@ut.ac.ir; Mazdak Hooshang, mazdak_hooshang@ut.ac.ir | ${ }^{1}$ Faculty of New Sciences and Technologies, University of Tehran, North Kargar St., Tehran, Iran. 
and aerodynamic conditions on the Stirling engine, it is difficult to provide a detailed mathematical model that expresses these equations. In this paper, the used model represents the dynamical equations governing the Stirling engine. Modeling of aerodynamic losses, frictional losses due to seals, and heat losses in the Stirling engine are very difficult due to the complexity of the type of gas flow inside the cycle, because the gas flow in the Stirling engine is oscillatory and non-parametric, and modeling is very complicated especially at high speeds. In addition, during the engine operation, the amount of gas flow, engine speed, and thermal flow rate also change, which adds to the complexity of the flow analysis.

One of the ways to achieve a comprehensive social and economic development in today's world is the existence of sustainable and reliable sources of energy $[12,13]$. Among the various types of renewable energy, solar energy has become more widely considered because of its direct conversion to electricity and heat, its simplicity of use, its storage capacity and its endlessness, so that in recent decades a lot of research has been done on solar energy systems in the world. Using solar energy as the heat source is growing rapidly around the world [14]; therefore, using Stirling engine with solar energy as the heat source can be a very good choice.

Many attempts were made to optimize the performance of Stirling engines [15]. Karabulut et al. [16] have tried to improve the performance of a beta-type Stirling engine by mean of displacer surface treatment. Three different displacers with different surface treatments were manufactured. The highest power engine power was obtained using the knurled displacer as $250 \mathrm{~W}$ at $545 \mathrm{rpm}$ speed. Gheith et al. [17] examined the effect of four materials of aluminum, stainless steel, monel 400 , and copper as the regenerator material. Each of these materials is individually examined on a gamma Stirling engine under the same conditions, among which Monel 400 and stainless steel are selected as a better regenerator materials.

Anderson et al. [18] studied the simulation of the Stirling engine. In their simulation, they used a simplified model of the Stirling engine. The model has been investigated using finite volume method. In this simulation, differential equations governing the model have been extracted using the mass and energy conservation equations. Finally, the results of this study are presented as diagrams containing temperature variations along the regenerator. Karabulut et al. [19] have analyzed a Martini-type Stirling engine performane and thermal efficiency at different speeds. The results show that increasing the regenerator heat area leads to increasing the thermal efficiency of the Martini Striling engine. Altin et al. [20] have developed a thermodynamic-dynamic simulation software to better optimize the performance of an alpha-type Stirling engine. As a result of their study, the engine power output of the alpha-type Stirling engine was improved by $5.6 \%$, $1 \%$ and $2.4 \%$ increments.

Ahmadi et al. [21] have studied Stirling heat engine using fininte speed thermodynamic analysis. This method is based on the first thermodynamic law. The results show that based on this method, the optimal performance of the Stirling heat engine is investigated along with the effects of the major parameters. Ferreira et al. [22] have studied the thermodynamic and economic optimization of a solar-powered Stirling engine for micro-cogeneration with the aim of optimizing the system for the best economical outcome. Hachem et al. [23] have studied a Stirling refrigerator theoretically and experimentally with the aim of investigating the cooling capacity, COP and optimizing the refrigeration power.

Bin-Nun et al. [24] used laminate screen matrix regenerator instead of wire-welded regenerator in their research. They attempted to increase the thermal efficiency by replacing the thermal regenerator type. Costa et al. [25] investigated the drop in the pressure of wired regenerators. With respect to the Navier-Stokes equations, the governing equations of this phenomenon are derived. Solving these equations using a finite volume method is carried out. Kato [26] has studied low-temperature Stirling engines. In his article, he uses the flat-plate walls as heat exchangers and directly connects the hot and cold sources to the cylinder.

Berchowitz et al. [27] used Stirling refrigerator as an alternative to low-temperature freezers. By removing the old system in these freezers, which used two compressors to provide the required cooling, in addition to significantly reducing the required electrical energy by reducing the volume and mass of the device, the amount of produced $\mathrm{CO}_{2}$ was reduced during the production cycle.

The purpose of this paper is to investigate the effect of different operating fluids in different pressures and cycles on the amount of work produced by a Stirling engine that uses a solar thermal heat source to provide heat. The Stirling engine used here is gamma type and the code has been already validated on a ST500 Stirling engine in our previous works $[28,29]$. In this paper, the proposed Stirling engine is investigated for heating using the Nlog code. In addition, experimental results which were validated in our prevoius works [28] using solar energy are presented in the current study. It is noteworthy to mention that the heat source for the Nlog code can be different, for example biomass, geothermal or even industrial waste heat.

The models that have been proposed so far are mainly for investigating engine behavior and analyzing the effect of changes in engine design parameters on engine performance, for example piston diameter, stroke length or regenerator area. In this paper, the focus is more on 
examining the operating variables that affect the efficiency and output power of the engine, such as operating temperature, speed and working fluid in different pressures. In Sect. 2 the theory in which the paper is written is explained. Section 3 explains the experimental setup and experimental results. Section 4 explains the results and discussion which the effects of working fluid and engine speed are discussed is this section.

\section{Theory}

This paper uses a code called Nlog code that is written in MATLAB programming environment and analyzes the proposed Stirling engine. This code has been written and validated by the authors of the current paper in the past works [28-30].

In this code, the third-order equations of continuity, momentum and energy are used to analyze the Stirling engine. The Nlog code divides all channels and gas pipelines of the engine into the control volumes, and determines the dynamic and thermodynamic parameters for each control volume by solving the corresponding equation [30].

\section{Experimental setup}

\subsection{Setup description}

In this study, a ST500 Stirling engine is used which has been manufactured by Irankhodro Research and Development Co. Specifications for these motors are given in Table 1.

Table 1 Technical specification of the Stirling engine used in this research

\begin{tabular}{lll}
\hline No & Engine technical specification & Value \\
\hline 1 & Type & $\begin{array}{l}\text { Gamma } \\
\text { Helium, Nitrogen and } \\
\text { Hydrogen }\end{array}$ \\
3 & Working fluid & Water \\
3 & Cooling substance & $0.075 \mathrm{~m}$ \\
4 & Power piston stroke & $0.075 \mathrm{~m}$ \\
5 & Displacer stroke & $90^{\circ}$ \\
6 & Phase angle & Tube $(6 \mathrm{~mm} \mathrm{dia.}) \times 20$ \\
7 & Heater type & Duct $\left(13 \mathrm{~mm}^{2}\right.$ section \\
8 & Cooler type & area $) \times 144$ \\
9 & Regenerator material & Steel matrix $(0.96$ porosity $)$ \\
10 & Energy source & Solar energy \\
11 & Heater temperature & $750^{\circ} \mathrm{C}$ \\
12 & Cooler temperature & $40^{\circ} \mathrm{C}$ \\
\hline
\end{tabular}

Figure 1 shows the ST500 Stirling engine used in the test. This figure shows various parts of the Stirling engine, including the following: heater, cooler, regenerator, flywheel and piston chamber.

\subsection{Experimental results}

The experimental results are taken from the previous studies by the authors [28]. Different parameters of the experimet and the results are described below:

\subsubsection{Initial and boundary conditions}

All of the required initial and boundary conditions have been measured from the test setup for the considered experiment. These conditions are shown in Table 2.

\subsubsection{Comparison between the simulation and experimental results}

For the above conditions mentioned in Table 2, the setup was run and experimental results were obtained. Also, the Nlog code was run and the the simulation results are shown in Table 3.

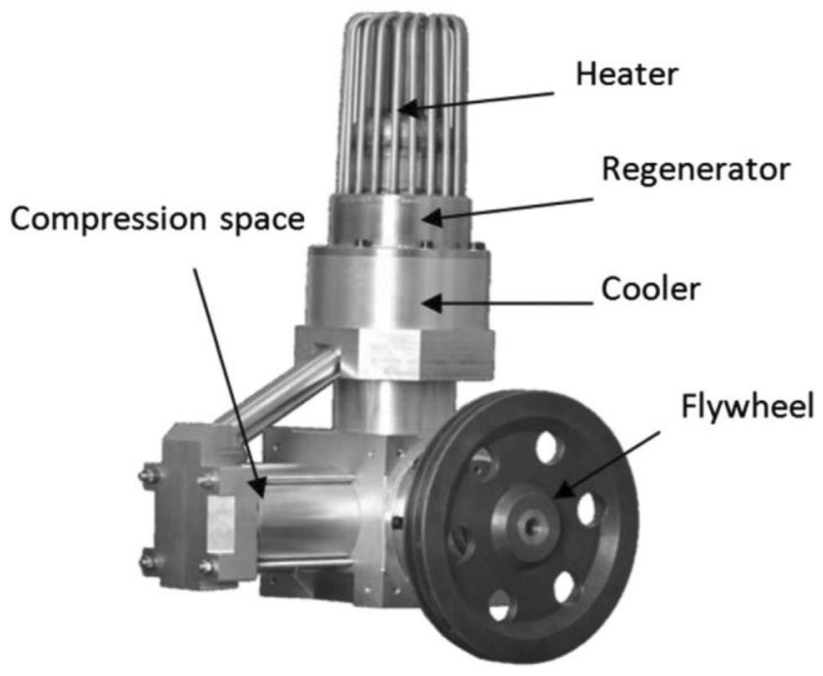

Fig. 1 ST500 Stirling engine

Table 2 Different initial and boundary conditions [28]

\begin{tabular}{ll}
\hline Charge pressure (bar) & 8.1 \\
Coolant entrance temperature $\left({ }^{\circ} \mathrm{C}\right)$ & 33.5 \\
Coolant exit temperature $\left({ }^{\circ} \mathrm{C}\right)$ & 41 \\
Heater tip temperature $\left({ }^{\circ} \mathrm{C}\right)$ & 393 \\
Heater base temperature $\left({ }^{\circ} \mathrm{C}\right)$ & 353 \\
Initial rotational speed $(\mathrm{rpm})$ & 970 \\
\hline
\end{tabular}


Table 3 Experimental and simulation results [28]

\begin{tabular}{lll}
\hline Simulation & Rejected heat rate $(\mathrm{kW})$ & 3.331 \\
& Power $(\mathrm{kW})$ & 0.44 \\
Experiment & Rejected heat rate $(\mathrm{kW})$ & 2.94 \\
& Power $(\mathrm{kW})$ & 0.4 \\
Error & Rejected heat rate $(\mathrm{kW})$ & 13.2 \\
& Power $(\%)$ & 10 \\
\hline
\end{tabular}

As shown in Table 3, the experimental and simulation results for the mentioned condition almost agree with each other. The rejected heat rate error and power error are $13.2 \%$ and $10 \%$, respectively. Based on these results the Nlog code was validated in our previous study [28].

Also, as an example of the comparison between the experimental results and Nlog code result, the pressurecrank angle diagram is shown in Fig. 2. The experimental and simulation results have good agreement with each other with maximum error of $2 \%$.

\section{Results and discussion}

As mentioned earlier, in this research, the Nlog code is used for simulating Stirling engine. Hydrogen, nitrogen and helium are used as the working fluids in three different charge pressures for different heating and cooling sources, and their graphs are presented for each case. The heater and cooler temperature for all the cases are considered to be $725^{\circ} \mathrm{C}$ and $40^{\circ} \mathrm{C}$, respectively.

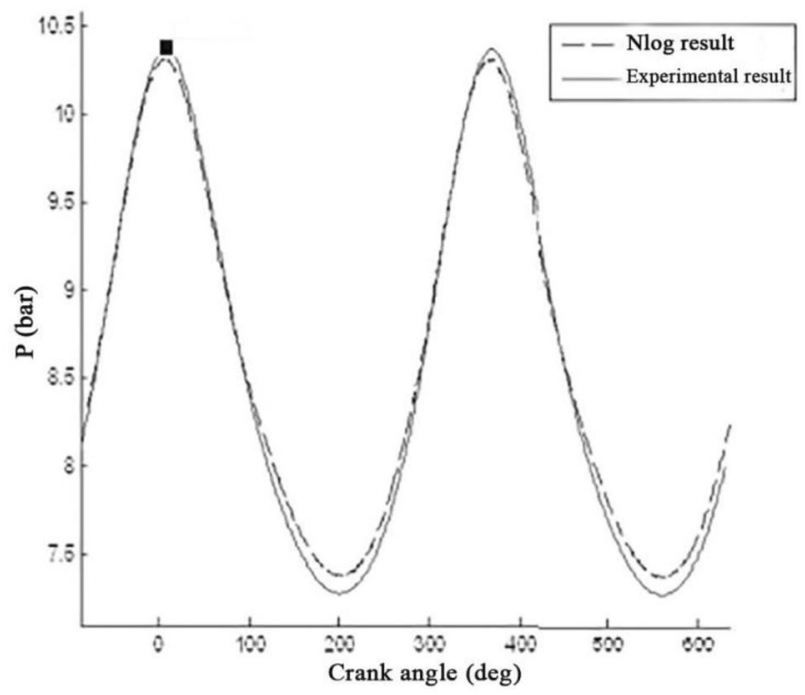

Fig. 2 Comparison between simulation and experimental pressure variation results

\subsection{Effect of engine speed}

In this section, the effect of three different working fluids is investigated at different engine speeds.

\subsubsection{Helium as the working fluid}

Helium is used as one of the most commonly working fluids in Stirling engines. The specific heat at constant pressure and volume for this fluid are 5195 and $3117 \mathrm{~J} / \mathrm{kg} \mathrm{K}$, respectively.

The output work per cycle is shown in Fig. 3, in terms of pressure in 800,970 and $1300 \mathrm{rpm}$. As shown in this figure, the output work increases with increasing the charge pressure of the engine. Because the pressure is an important factor in Stirling engine.

\subsubsection{Nitrogen as the working fluid}

As discussed before, nitrogen is used as the working fluid in the Stirling engine to investigate the effect of this fluid on the output power of the engine. The specific heat at constant pressure and volume for this fluid are 1040 and $743 \mathrm{~J} / \mathrm{kg} \mathrm{K}$, respectively.

The output work per cycle for nitrogen as the working fluid is shown in Fig. 4, in terms of pressure in 800, 970, and $1300 \mathrm{rpm}$. Like helium, the output work per cycle increases with increasing the charge pressure of the engine.

\subsubsection{Hydrogen as the working fluid}

Hydrogen is another working fluid used in the proposed Stirling engine to further investigate the effect of working fluid on the Stirling engine performance.

The experiments for helium and nitrogen were performed previously by the authors in other conditions [28].

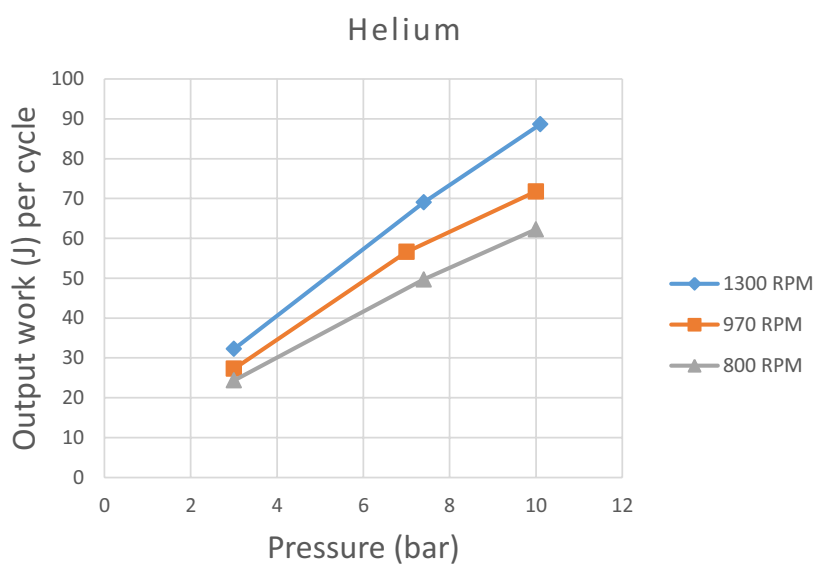

Fig. 3 Output work per cycle versus pressure for helium gas 
Nitrogen

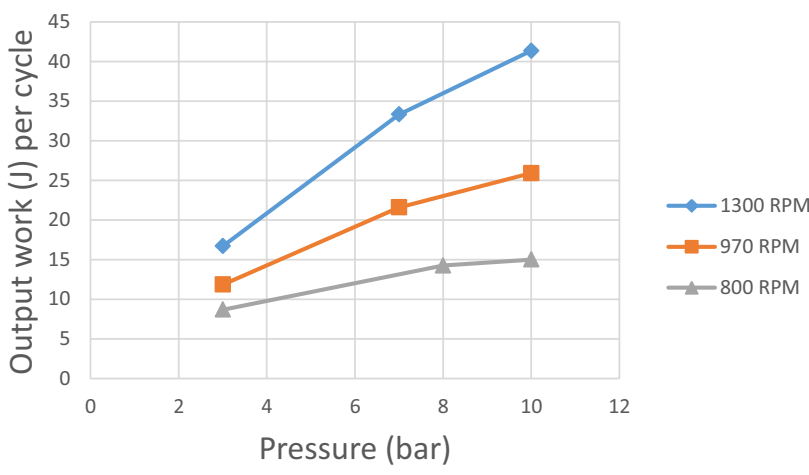

Fig. 4 Output work per cycle versus pressure for nitrogen gas

Hydrogen

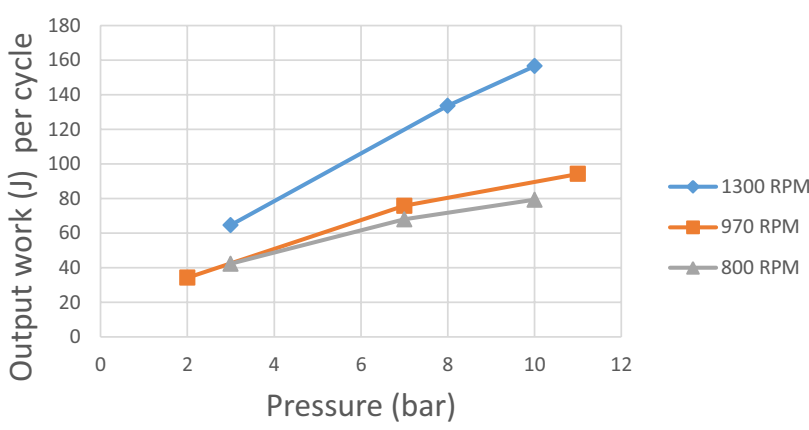

Fig. 5 Output work per cycle versus pressure for hydrogen gas

Hydrogen as the working fluid has better properties but because of being highly flammable, it was not possible for the authors to apply it to experimental setup. However, by using the Nlog code as the simulation software, the effect of hydrogen as working fluid in the Stirling engine is studied in the present study. The specific heat at constant pressure and volume for this fluid are 14,307 and 10,183 J/kg K, respectively. The output work per cycle for hydrogen as the working fluid is shown in Fig. 5 , in terms of pressure in 800,970 and $1300 \mathrm{rpm}$. Like helium and nitrogen, the output work per cycle increases by increasing the charge pressure of the engine.

\subsection{Effect of working fluid}

In this section the effect of different working fluids is investigated in ST500 Stirling engine considering several motor rotational speeds. As before, helium, nitrogen, and hydrogen are investigated in 1300, 970 and $870 \mathrm{rpm}$.

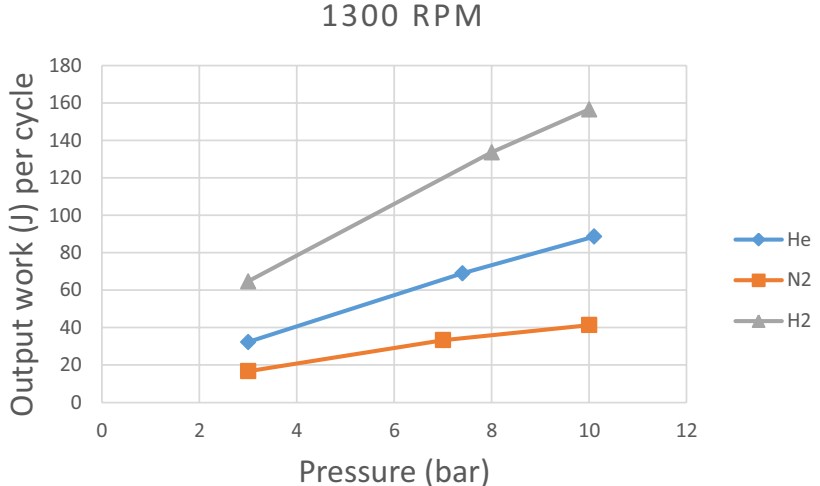

Fig. 6 Output work per cycle versus charge pressure at $1300 \mathrm{rpm}$ rotational speed

970 RPM

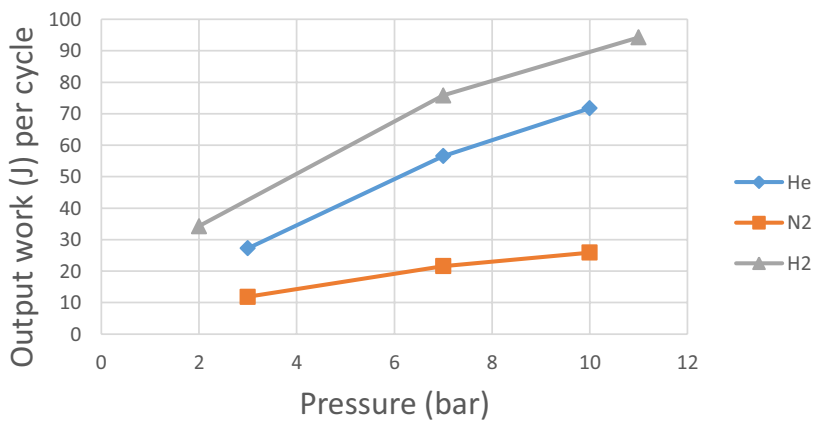

Fig. 7 Output work per cycle versus charge pressure at $970 \mathrm{rpm}$ rotational speed

\subsection{1 $1300 \mathrm{rpm}$ rotational speed}

Figure 6 shows the output power per cycle versus charge pressure of the engine in $1300 \mathrm{rpm}$. As shown in this figure, hydrogen is considered to be the best working fluid in the proposed engine. After that, helium is the second working fluid that performs better than nitrogen. Finally, nitrogen is ranked as the third working fluid in terms of output power per cycle.

\subsection{2 $970 \mathrm{rpm}$ rotational speed}

Figure 7 shows the output power per cycle versus charge pressure of the engine in $970 \mathrm{rpm}$. As shown in this figure, $\mathrm{H}_{2}$ is the best working fluid in the proposed engine. After that, $\mathrm{He}$ is the second working fluid that performs better than $\mathrm{N}_{2}$ at $970 \mathrm{rpm} . \mathrm{N}_{2}$ is the third working fluid in terms of output work per cycle. 
800 RPM

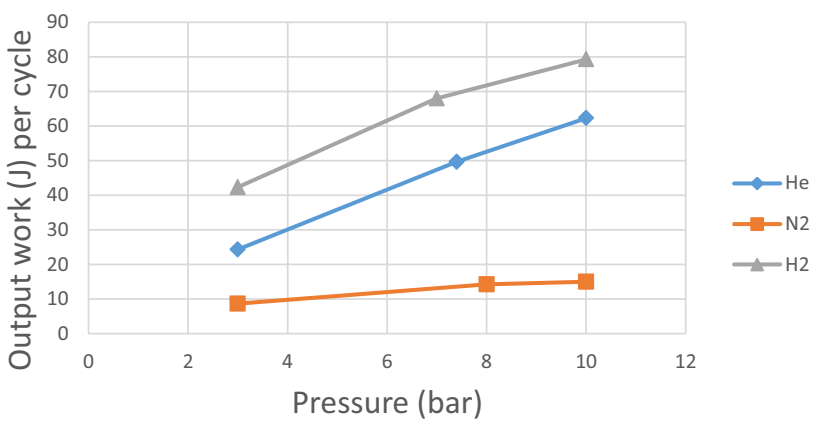

Fig. 8 Output work per cycle versus charge pressure at $800 \mathrm{rpm}$ rotational speed

\subsection{3 $800 \mathrm{rpm}$ rotational speed}

Figure 8 shows the output power per cycle versus charge pressure of the engine in $800 \mathrm{rpm}$. As shown in this figure, hydrogen is the best working fluid in the proposed engine like the two previous cases. After that, helium is the second working fluid that performs better than $\mathrm{N}_{2}$ at 800 rpm. He and $\mathrm{H}_{2}$ perform better than $\mathrm{N}_{2}$ significantly.

\subsection{Comparison of different working fluids and engine rotational speeds}

Figure 9 shows output work per cycle for different working fluids and engine rotational speeds at the pressure of 10 bar. As shown, hydrogen has the best performance as the working among the three tested working fluids with output work per cycle of $156.6 \mathrm{~J}$ per cycle. After hydrogen, helium is the second appropriate working fluid used in this study. The third appropriate working fluid is nitrogen.

\section{Conclusion}

In this study, simulation software for gamma-type Stirling engine was used to investigate the effect of pressure, speed and working fluid on the Stirling engine output power. For this purpose, a code was used which was previously written and validated by the authors of the current paper. Stirling engines are highly dependent on heater temperature. The temperature of the heater section was considered to be $725^{\circ} \mathrm{C}$ which is a suitable temperature for the Stirling engine. It is noteworthy to mention that the above mentioned experimental results for solar energy were performed by the authors in previous works, however, this paper is based on silmulation results.

It is concluded that engine performance depends highly on the working fluid. The fluid in which the proposed Stirling engine had the best performance was hydrogen. However, hydrogen is not widely used as a working fluid in Stirling engines because of its high risk of flammability. It was also found that the proposed engine had better performance at higher pressures. The engine speed has a great impact on the performance of the Stirling engine, so that the proposed Stirling engine had the best performance at $1300 \mathrm{rpm}$, using hydrogen and maximum standard gas pressure among all investigated cases in this paper. After hydrogen as the best working fluid, helium is the second working fluid. As mentioned above, considering the flammability of hydrogen, helium is considered to be the best choice to be used in the Stirling engines.
Fig. 9 Output work per cycle versus working fluids for different rotational speeds (charge pressure 10 bar)

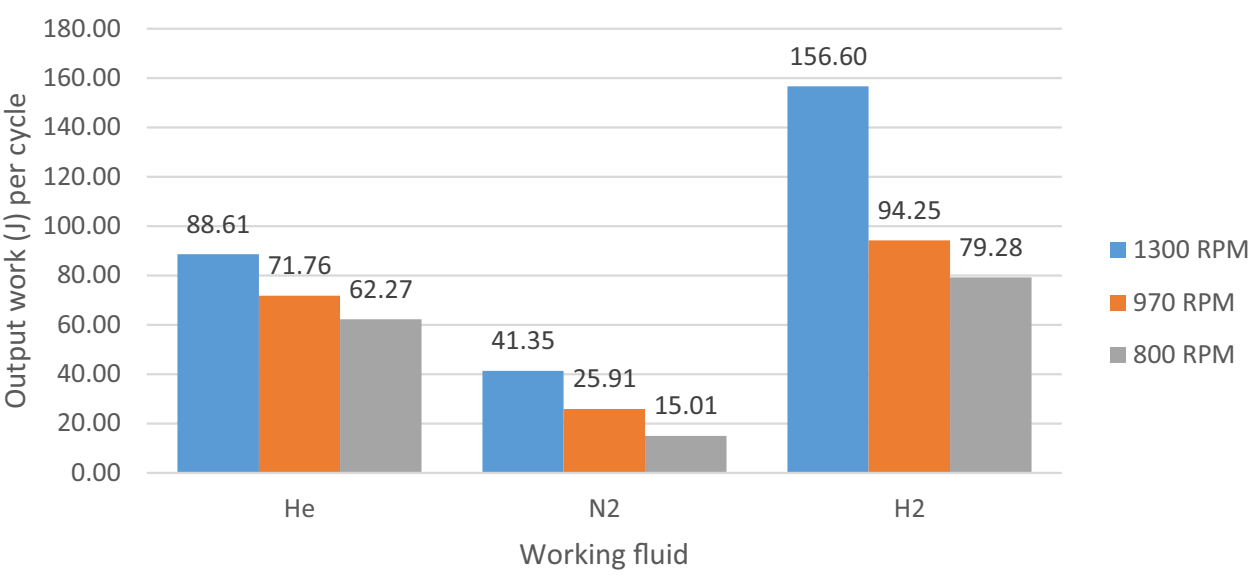


Acknowledgements The authors would like to thank Azhineh Micro System Company for its supports.

\section{Compliance with ethical standards}

Conflict of interest The authors declare that there's no conflict of interests that could affect the work reported in this paper.

\section{References}

1. Ahmadi MH, Mohammadi AH, Pourkiaei SM (2016) Optimisation of the thermodynamic performance of the Stirling engine. Int J Ambient Energy 37(2):149-161

2. Sier R (1999) Hot air caloric and Stirling engines: history. LA Mair, Chelmsford

3. Ahmadi MH, Ahmadi MA, Mellit A, Pourfayaz F, Feidt M (2016) Thermodynamic analysis and multi objective optimization of performance of solar dish Stirling engine by the centrality of entransy and entropy generation. Int J Electr Power Energy Syst 78:88-95

4. Kongtragool B, Wongwises S (2003) A review of solar-powered Stirling engines and low temperature differential Stirling engines. Renew Sustain Energy Rev 7(2):131-154

5. Li R, Grosu L, Queiros-Conde D (2016) Multi-objective optimization of Stirling engine using Finite Physical Dimensions Thermodynamics (FPDT) method. Energy Convers Manag 124:517-527

6. Szczygieł I, Stanek W, Szargut J (2016) Application of the Stirling engine driven with cryogenic exergy of LNG (liquefied natural gas) for the production of electricity. Energy 105:25-31

7. Schmidt G (1871) The theory of Lehmann's calorimetric machine. Zeitschrift Des Vereines Deutscher Ingenieure 15(1):98-112

8. Finkelstein T (1967) Thermodynamic analysis of Stirling engines. J Spacecraft Rockets 4(9):1184-1189

9. Li X et al (2017) Experimental validation and numeric optimization of a resonance tube-coupled duplex Stirling cooler. Appl Energy 207:604-612

10. Ahmadi MA, Ashouri M, Sadatsakkak SA, Ahmadi MH (2016) Optimization performance of irreversible refrigerators base on evolutionary algorithm. Mech Ind 17(2):209

11. Noorbakhsh M, Moradi HR (2019) Design and optimization of multi-stage manufacturing process of stirling engine crankshaft. SN Appl Sci 2(1):65

12. Mehrpooya M, Sharifzadeh MMM, Katooli MH (2018) Thermodynamic analysis of integrated LNG regasification process configurations. Prog Energy Combust Sci 69:1-27

13. Katooli MH, Askari Moghadam R, Hajinezhad A (2019) Proposing and theoretical analysis of two coupled stirling engines for converting heat to coldness. Sharif J Mech Eng 35(3):99-105

14. Ranjbaran P, Yousefi H, Gharehpetian G, Astaraei FR (2019) A review on floating photovoltaic (FPV) power generation units. Renew Sustain Energy Rev 110:332-347

15. Sa'ed A, Tlili I (2015) Numerical investigation of working fluid effect on Stirling engine performance. Int J Therm Environ Eng 10(1):31-36
16. Karabulut H, Çınar C, Aksoy F, Yücesu HS (2010) Improved Stirling engine performance through displacer surface treatment. Int $J$ Energy Res 34(3):275-283

17. Gheith R, Aloui F, Nasrallah SB (2012) Study of the regenerator constituting material influence on a Gamma type Stirling engine. J Mech Sci Technol 26(4):1251-1255

18. Andersen SK, Carlsen H, Thomsen PG (2006) Preliminary results from simulations of temperature oscillations in Stirling engine regenerator matrices. Energy 31(10-11):1371-1383

19. Karabulut H, Okur M, Ozdemir AO (2019) Performance prediction of a Martini type of Stirling engine. Energy Convers Manag 179:1-12

20. Altin M, Okur M, Ipci D, Halis S, Karabulut H (2018) Thermodynamic and dynamic analysis of an alpha type Stirling engine with Scotch Yoke mechanism. Energy 148:855-865

21. Ahmadi $M H$, Ahmadi MA, Pourfayaz F, Bidi $M$, Hosseinzade $H$, Feidt M (2016) Optimization of powered Stirling heat engine with finite speed thermodynamics. Energy Convers Manag 108:96-105

22. Ferreira AC, Nunes ML, Teixeira JC, Martins LA, Teixeira SF (2016) Thermodynamic and economic optimization of a solar-powered Stirling engine for micro-cogeneration purposes. Energy 111:1-17

23. Hachem H, Gheith R, Aloui F, Nasrallah SB (2017) Optimization of an air-filled Beta type Stirling refrigerator. Int J Refrig 76:296-312

24. Bin-Nun U, Manitakos D (2004) Low cost and high performance screen laminate regenerator matrix. Cryogenics 44(6-8):439-444

25. Costa S, Barrutia H, Esnaola JA, Tutar M (2013) Numerical study of the pressure drop phenomena in wound woven wire matrix of a Stirling regenerator. Energy Convers Manag 67:57-65

26. Kato Y (2016) Indicated diagrams of a low temperature differential Stirling engine using flat plates as heat exchangers. Renew Energy 85:973-980

27. Berchowitz DM, Kwon Y (2012) Environmental profiles of Stirling-cooled and cascade-cooled ultra-low temperature freezers. Sustainability 4(11):2838-2851

28. Hooshang M, Moghadam RA, AlizadehNia S (2016) Dynamic response simulation and experiment for gamma-type Stirling engine. Renew Energy 86:192-205

29. Hooshang M, Askari Moghadam R, Alizadeh Nia S, Masouleh MT (2015) Optimization of Stirling engine design parameters using neural networks. Renew Energy 74:855-866

30. Katooli MH, Moghadam RA, Hajinezhad A (2019) Simulation and experimental evaluation of Stirling refrigerator for converting electrical/mechanical energy to cold energy. Energy Convers Manag 184:83-90

Publisher's Note Springer Nature remains neutral with regard to jurisdictional claims in published maps and institutional affiliations. 